\title{
Cost and attainability of meeting stringent climate targets without overshoot
}

\author{
Keywan Riahi $\mathbb{1}^{1,2} \bowtie$, Christoph Bertram $\mathbb{1}^{3}$, Daniel Huppmann ${ }^{\circledR 1}$, Joeri Rogelj ${ }^{1,4}$, Valentina Bosetti ${ }^{5,6}$, \\ Anique-Marie Cabardos', Andre Deppermann ${ }^{10}$ ', Laurent Drouet $\mathbb{D}^{6}$, Stefan Frank', Oliver Fricko (1D) , \\ Shinichiro Fujimori ${ }^{1,7,8}$, Mathijs Harmsen $\oplus^{9,10}$, Tomoko Hasegawa ${ }^{8,11}$, Volker Krey ${ }^{1,12}$, \\ Gunnar Luderer ${ }^{3,13}$, Leonidas Paroussos ${ }^{14}{ }^{14}$, Roberto Schaeffer (15) ${ }^{15}$, Matthias Weitzel (16) \\ Bob van der Zwaan $\mathbb{1}^{17,18,19}$, Zoi Vrontisi ${ }^{14}$, Francesco Dalla Longa ${ }^{17}$, Jacques Després ${ }^{16}$, \\ Florian Fosse ${ }^{10}{ }^{16}$, Kostas Fragkiadakis ${ }^{14}{ }^{14}$, Mykola Gusti ${ }^{1,20}$, Florian Humpenöder ${ }^{(1)}{ }^{3}$, \\ Kimon Keramidas ${ }^{16}$, Paul Kishimoto', Elmar Kriegler $\mathbb{D}^{3,21}$, Malte Meinshausen $\mathbb{1}^{3,22}$, \\ Larissa P. Nogueira ${ }^{17}{ }^{17}$, Ken Oshiro $\mathbb{D}^{7,8}$, Alexander Popp $\mathbb{1}^{3}$, Pedro R. R. Rochedo ${ }^{15}$, Gamze Ünlü $\mathbb{1}^{1}$, \\ Bas van Ruijven ${ }^{\mathbb{1}}$ ', Junya Takakura ${ }^{8}{ }^{8}$, Massimo Tavoni ${ }^{6,23}$, Detlef van Vuuren ${ }^{9,10}$ and \\ Behnam Zakeri ${ }^{1}$ 1
}

Global emissions scenarios play a critical role in the assessment of strategies to mitigate climate change. The current scenarios, however, are criticized because they feature strategies with pronounced overshoot of the global temperature goal, requiring a long-term repair phase to draw temperatures down again through net-negative emissions. Some impacts might not be reversible. Hence, we explore a new set of net-zero $\mathrm{CO}_{2}$ emissions scenarios with limited overshoot. We show that upfront investments are needed in the near term for limiting temperature overshoot but that these would bring long-term economic gains. Our study further identifies alternative configurations of net-zero $\mathrm{CO}_{2}$ emissions systems and the roles of different sectors and regions for balancing sources and sinks. Even without net-negative emissions, $\mathrm{CO}_{2}$ removal is important for accelerating near-term reductions and for providing an anthropogenic sink that can offset the residual emissions in sectors that are hard to abate.

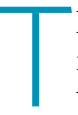
he Paris Agreement sets the framework for international climate action. Within that context, countries are aiming to hold warming well below $2^{\circ} \mathrm{C}$ and pursue limiting it to $1.5^{\circ} \mathrm{C}$. How such global temperature outcomes can be achieved has been explored widely in the scientific literature ${ }^{1-4}$ and assessed by the IPCC, for example, in its Fifth Assessment Report (AR5; ref. ${ }^{5}$ ) and its Special Report on Global Warming of $1.5^{\circ} \mathrm{C}$ (SR1.5; ref. ${ }^{6}$ ). Studies explore aspects of the timing and costs of emissions reductions and the contribution of different sectors ${ }^{3,7,8}$. However, there has been critique that, with the exception of a few notable studies ${ }^{9-12}$, the scenarios in the literature first exceed the prescribed temperature limits in the hope of recovering from this overshoot later through net-negative emissions $^{13-16}$. Some pioneering studies ${ }^{10-12}$ have explored implications of limiting overshoot through, for example, zero emissions goals, or have looked into the role of bioenergy with carbon capture and storage (BECCS) in reaching different temperature targets ${ }^{9}$. All these studies have relied on one or two models and/or a limited set of temperature targets.

We bring together nine international modelling teams and conduct a comprehensive modelling intercomparison project (MIP) on this topic. Specifically, we explore mitigation pathways for reaching different temperature change targets with limited overshoot. We do this by adopting the scenario design from ref. ${ }^{11}$ and contrast scenarios with a fixed remaining carbon budget until the time when net-zero $\mathrm{CO}_{2}$ emissions (net-zero budget scenarios) are reached with scenarios that use an end-of-century budget design. The latter carbon budget for the full century permits the budget to be temporarily overspent, as long as net-negative $\mathrm{CO}_{2}$ emissions (NNCE)

\footnotetext{
International Institute for Applied Systems Analysis (IIASA), Laxenburg, Austria. ${ }^{2}$ Graz University of Technology, Graz, Austria. ${ }^{3}$ Potsdam Institute for Climate Impact Research (PIK), Member of the Leibniz Association, Potsdam, Germany. ${ }^{4}$ Grantham Institute for Climate Change and the Environment, Imperial College London, London, UK. ${ }^{5}$ Department of Economics and IGIER, Bocconi University, Milan, Italy. ${ }^{6}$ RFF-CMCC European Institute of Economics and the Environment, Centro Euro-Mediterraneo sui Cambiamenti Climatici, Milan, Italy. ${ }^{7}$ Department of Environmental Engineering, Kyoto University, Katsura Campus, Nishikyo-ku, Kyoto, Japan. ${ }^{8}$ Center for Social and Environmental Systems Research, National Institute for Environmental Studies (NIES), Tsukuba, Japan. ${ }^{9}$ PBL Netherlands Environmental Assessment Agency, The Hague, the Netherlands. ${ }^{10}$ Copernicus Institute for Sustainable Development, Utrecht University, Utrecht, the Netherlands. ${ }^{11}$ College of Science and Engineering, Ritsumeikan University, Kyoto, Japan. ${ }^{12}$ Industrial Ecology Programme and Energy Transitions Initiative, Norwegian University of Science and Technology (NTNU), Trondheim, Norway. ${ }^{13}$ Technische Universität Berlin, Berlin, Germany. ${ }^{14} \mathrm{E} 3$ Modelling, Athens, Greece. ${ }^{15} \mathrm{COPPE}$, Universidade Federal do Rio de Janeiro, Rio de Janeiro, Brazil. ${ }^{16}$ European Commission, Joint Research Centre (JRC), Seville, Spain. ${ }^{17}$ TNO Energy Transition, Amsterdam, the Netherlands. ${ }^{18}$ University of Amsterdam, Amsterdam, the Netherlands. ${ }^{19} \mathrm{Johns}$ Hopkins University, Bologna, Italy. ${ }^{20}$ Lviv Polytechnic National University, Lviv, Ukraine. ${ }^{21}$ Faculty of Economics and Social Sciences, University of Potsdam, Potsdam, Germany. ${ }^{22}$ Australian-German Climate \& Energy College, University of Melbourne, Parkville, Victoria, Australia. ${ }^{23}$ Politecnico di Milano, Department of Management, Economics and Industrial Engineering, Milan, Italy. ${ }^{凶}$ e-mail: riahi@iiasa.ac.at
} 
Table 1 | Scenario narratives and the corresponding range of attainable $2030 \mathrm{CO}_{2}$ emissions and the attainable carbon budgets (2020-2100)

\begin{tabular}{|c|c|c|c|c|c|}
\hline $\begin{array}{l}\text { Scenario } \\
\text { name (no. of } \\
\text { scenarios) }\end{array}$ & Narrative & $\begin{array}{l}\text { Near-term policy } \\
\text { assumptions, } \\
2020-2030\end{array}$ & $\begin{array}{l}\text { Long-term climate policy } \\
\text { assumptions }\end{array}$ & $\begin{array}{l}2030 \mathrm{GHG} \\
\text { emissions range } \\
\left(\mathrm{GtCO}_{2} \mathrm{e}\right)\end{array}$ & $\begin{array}{l}\text { Range of cumulative } \\
\mathrm{CO}_{2} \text { emissions } \\
(2020-2100 \text {, } \\
\left.\mathrm{GtCO}_{2}\right)^{\mathrm{a}}\end{array}$ \\
\hline NPi (8) & $\begin{array}{l}\text { GHG emissions follow } \\
\text { currently implemented } \\
\text { national policies (NPi). No } \\
\text { additional new policies are } \\
\text { assumed in the future. }\end{array}$ & $\begin{array}{l}\text { No additional policies } \\
\text { compared to today. }\end{array}$ & $\begin{array}{l}\text { No additional policies } \\
\text { compared to those } \\
\text { implemented today. }\end{array}$ & $54.1-65$ & $3,552-4,645$ \\
\hline NDC (8) & $\begin{array}{l}\text { Development to } 2030 \text { guided } \\
\text { by NDCs. No additional } \\
\text { policies relative to NDCs are } \\
\text { assumed after } 2030 \text {. }\end{array}$ & $\begin{array}{l}\text { Achievement of NDCs } \\
\text { by } 2030 .\end{array}$ & $\begin{array}{l}\text { No additional policies after } \\
2030 \text { beyond the NDCs } \\
\text { (including emission (intensity) } \\
\text { targets but also sectoral } \\
\text { targets mentioned in NDCs). }\end{array}$ & $46.8-56.3$ & $2,162-3,872$ \\
\hline $\begin{array}{l}\text { End-of-century } \\
\text { budget (a, 101; } \\
\text { b, 84) }\end{array}$ & $\begin{array}{l}\text { The 'end-of-century budget' } \\
\text { scenarios assume long-term } \\
\text { climate policies that limit } \\
\text { cumulative } \mathrm{CO}_{2} \text { emissions } \\
\text { over the full course of the } \\
\text { century. The scenarios may } \\
\text { comprise high temperature } \\
\text { overshoot and global NNCE in } \\
\text { the second half of the century. }\end{array}$ & $\begin{array}{l}\text { Two variants are } \\
\text { explored with either (a) } \\
\text { immediate introduction } \\
\text { of climate policies as of } \\
2020 \text { or (b) near-term } \\
\text { policies follow the } \\
\text { NDC to } 2030 \text { and } \\
\text { more stringent policies } \\
\text { are introduced only } \\
\text { thereafter. }\end{array}$ & $\begin{array}{l}\text { Long-term } \mathrm{CO}_{2} \text { pathway } \\
\text { constrained by cumulative } \\
\mathrm{CO}_{2} \text { emissions over the entire } \\
\text { century, allowing temperature } \\
\text { overshoot and NNCE. Non- } \mathrm{CO}_{2} \\
\text { emissions are priced at the } \\
\text { same level as } \mathrm{CO}_{2} \text { except } \\
\text { non- } \mathrm{CO}_{2} \text { emissions in the } \\
\text { agricultural sector, where } \mathrm{GHG} \\
\text { prices are capped at }<\mathrm{US} \$ 200 \\
\text { per } \mathrm{CCO}_{2} \mathrm{e} \text { (limiting negative } \\
\text { impacts on food security due } \\
\text { to high } \mathrm{GHG} \text { prices). }\end{array}$ & $\begin{array}{l}\text { (a) NPi: } 24.3-58.3 \\
\text { (b) Near-term } \\
\text { emissions } \\
\text { depend on NDC } \\
\text { implementation } \\
\text { (above) }\end{array}$ & $\begin{array}{l}\text { Attainable range } \\
\text { depends on } \\
\text { near-term policy } \\
\text { assumptions: } \\
\text { (a) NPi: } \\
200-3,000 \mathrm{GtCO}_{2} \\
\text { (b) NDC: } \\
300-3,000 \mathrm{GtCO}_{2}\end{array}$ \\
\hline $\begin{array}{l}\text { Net-zero budget } \\
(a, 88 ; b, 62)\end{array}$ & $\begin{array}{l}\text { The 'net-zero budget' scenarios } \\
\text { assume climate policies that } \\
\text { limit the remaining cumulative } \\
\mathrm{CO}_{2} \text { emissions until carbon } \\
\text { neutrality (net-zero } \mathrm{CO}_{2} \\
\text { emissions) is reached. These } \\
\text { scenarios limit the temperature } \\
\text { overshoot and do not rely } \\
\text { on global NNCE to keep } \\
\text { warming below the intended } \\
\text { temperature limit. }\end{array}$ & $\begin{array}{l}\text { Two variants are explored } \\
\text { with either (a) immediate } \\
\text { introduction of climate } \\
\text { policies as of } 2020 \text { or (b) } \\
\text { near-term policies follow } \\
\text { the NDC to } 2030 \text { and } \\
\text { more stringent policies } \\
\text { are introduced only } \\
\text { thereafter. }\end{array}$ & $\begin{array}{l}\text { Long-term } \mathrm{CO}_{2} \text { pathway } \\
\text { constrained by maximum } \\
\text { cumulative } \mathrm{CO}_{2} \text { emissions } \\
\text { until net-zero } \mathrm{CO}_{2} \text { emissions } \\
\text { are reached. } \mathrm{No} \mathrm{NNCE} \text { are } \\
\text { thus required for warming } \\
\text { to be limited to the intended } \\
\text { maximum level. Non- } \mathrm{CO}_{2} \\
\text { emissions assumptions are the } \\
\text { same as in the end-of-century } \\
\text { budget scenarios (above). }\end{array}$ & $\begin{array}{l}\text { (a) NPi: } 19.3-58.4 \\
\text { (b) Near-term } \\
\text { emissions } \\
\text { depend on NDC } \\
\text { implementation } \\
\text { (above) }\end{array}$ & $\begin{array}{l}\text { Attainable range } \\
\text { depends on } \\
\text { near-term policy } \\
\text { assumptions: } \\
\text { (a) NPi: } \\
\text { 400-3,000 } \mathrm{GtCO}_{2} \\
\text { (b) NDC: } \\
500-3,000 \mathrm{GtCO}_{2}\end{array}$ \\
\hline
\end{tabular}

aNumbers represent the attainable scenario space by the models (Supplementary Tables 2.1-1 and 2.1-2). The radiative forcing, temperature change and emissions ranges are shown in Supplementary Figs. 1.1-1 to 1.1-3.

bring back cumulative $\mathrm{CO}_{2}$ emissions to within the budget by 2100 . This approach dominates the current literature and leads to a temporary overshoot of the associated temperature target. Importantly, the earlier introduced 'net-zero budget scenarios' limit cumulative $\mathrm{CO}_{2}$ to a maximum without exceeding the emissions budget. These scenarios thus keep global warming below a certain threshold (without exceeding it) and stabilize the temperature thereafter.

The new pathways fill important knowledge gaps. First, they cover the range of carbon budgets consistent with low stabilization targets in a systematic way and across a wide range of diverse global models. The pathways thus explore important uncertainties, including the attainable scenario space across different models and target definitions. This information is critical for international assessments, such as those by the IPCC ${ }^{17}$. Secondly, we explore the impacts of the country pledges from the post-Paris process for the attainability of overshoot and non-overshoot targets. Thirdly, we investigate salient temporal trade-offs with respect to mitigation costs; and finally we explore distinct differences in terms of the possible regional and global designs of net-zero $\mathrm{CO}_{2}$ emissions systems. The main narratives of the pathways and assumptions are provided in Table 1.

\section{Implications for emissions pathways}

Reaching stringent temperature targets with limited overshoot, requires a pronounced acceleration of the near-term transformation towards net-zero $\mathrm{CO}_{2}$ emissions. Staying within a budget of $500 \mathrm{GtCO}_{2}$ (consistent with a median warming of $1.44-1.63^{\circ} \mathrm{C}$ ), for example, requires $\mathrm{CO}_{2}$ emissions to reach net zero between 2045 and 2065 (range across models). When an 'end-of-century' carbon budget is used, the time of reaching net-zero $\mathrm{CO}_{2}$ emissions is delayed between 5 and 15 years (to 2060-2070). This delay, combined with the higher emissions over that period, results in $0.08-0.16^{\circ} \mathrm{C}$ higher peak temperatures compared to scenarios that are identical in all but their allowance to overshoot the carbon budget.

A broad set of behavioural, biophysical, economic, geophysical, legal, political and technological factors render transformations to net zero more or less challenging ${ }^{18}$. The modelling exercise here informs primarily challenges related to economic, geophysical and technological feasibility. The lowest attainable net-zero $\mathrm{CO}_{2}$ emissions budget (limiting overshoot) is $400-800 \mathrm{GtCO}_{2}$ across the models (assuming immediate implementation of ambitious policies and a middle-of-the-road socioeconomic development ${ }^{19}$ ). 
This budget range corresponds to a median peak warming during the twenty-first century between 1.42 and $1.72^{\circ} \mathrm{C}$. Weak near-term policies that result in higher GHG emissions over the next decade, such as those implied by the current nationally determined contributions (NDCs), will affect the lowest attainable carbon budget. We estimate that the NDCs (Methods) will lead to GHG emissions of $46.8-56.3 \mathrm{GtCO}_{2}$ e by 2030 , which is substantially higher than the range of cost-effective emissions pathways consistent with $2{ }^{\circ} \mathrm{C}$ (25-48.6 $\left.\mathrm{GtCO}_{2} \mathrm{e}\right)$, let alone $1.5^{\circ} \mathrm{C}$, by $2030\left(19.4-35.3 \mathrm{GtCO}_{2} \mathrm{e}\right)$. We adopt the definition of 1.5 and $2{ }^{\circ} \mathrm{C}$ goals from the SR1.5 (Methods). Assuming NDCs are not tightened and comprehensive climate policies are thus delayed until after 2030, the lowest attainable net-zero $\mathrm{CO}_{2}$ budget across the models is $500-1,200 \mathrm{GtCO}_{2}$, which corresponds to a warming of 1.61 and $1.89^{\circ} \mathrm{C}$. Current NDCs thus put limiting warming to $1.5^{\circ} \mathrm{C}$ out of reach on the basis of the biophysical, economic, geophysical, technological and economic feasibility dimensions reflected by the models applied here. Other feasibility dimensions, such as behavioural, legal, political or social aspects, can affect these ranges further, although this study does not explore their impact.

The pathways feature net-negative emissions from a few megatons to $\sim 500 \mathrm{GtCO}_{2}$ across models, depicting a techno-economic potential for declining warming after its peak between 0.13 and $0.34^{\circ} \mathrm{C}$ by 2100 (Fig. 1b). This temperature reversal is mainly driven by NNCE but can also be partially the result of reductions in non- $\mathrm{CO}_{2}$ forcers $^{20}$ (Methods; see Supplementary Figs. 1.1-6,9,10 for the relationship between peak temperature, overshoot and NNCE).

The net-zero budget scenarios allow for the systematic quantification of the residual non- $\mathrm{CO}_{2}$ emissions consistent with different peak temperature levels (Fig. 1c). A large share of these residual non- $\mathrm{CO}_{2}$ emissions is caused by the agriculture, forestry and other land-use (AFOLU) sector, most prominently by enteric fermentation $\left(\mathrm{CH}_{4}\right)$ and fertilizer use $\left(\mathrm{N}_{2} \mathrm{O}\right)$. The annual residual non- $\mathrm{CO}_{2}$ emissions in the second half of the century range from slightly above 3 to $>10 \mathrm{GtCO}_{2} \mathrm{e}$ highlighting once more the dual importance of $\mathrm{CO}_{2}$ and non- $\mathrm{CO}_{2}$ mitigation measures (Fig. 1c). We emphasize that while our net-zero budget scenarios exclude NNCE, for many policy goals, including those of the Paris Agreement ${ }^{21}$ or the climate neutrality target of the $\mathrm{EU}^{22}$, NNCE are needed to balance residual non- $\mathrm{CO}_{2}$ emissions and reach net-zero greenhouse gas emissions ${ }^{16}$.

\section{Upfront costs and long-term economic benefits}

The IPCC AR5 emphasizes that mitigation costs would rise over time as a result of efforts to limit climate change ${ }^{5}$. These mitigation costs traditionally reflect the impacts on gross domestic product (GDP) while ignoring the benefits of mitigation due to avoided impacts ${ }^{5}$. Typically, relatively smaller mitigation costs are reported in the near term through to 2030 compared to the medium term (2050) or the very long term by $2100^{4,5,11,23}$. This evolution is primarily a result of most integrated assessment model (IAM) studies focusing on targets for the end of the century, which, by design, favours postponement of mitigation action until later in the century ${ }^{11,24}$.

Scenarios that limit temperature overshoot (that is, the net-zero budget scenarios), pace mitigation actions differently, requiring much more rapid emissions reductions in the near term (Fig. 1 and Supplementary Fig. 1.1-8). Avoiding overshoot is thus associated with higher upfront investments and higher near-term mitigation costs. We find that GDP in the near term is $0.5-4.8 \%$ lower in scenarios that keep warming below $1.5^{\circ} \mathrm{C}$ with no or limited overshoot and 0.1 to $\sim 1.6 \%$ lower in scenarios that limit warming to $2^{\circ} \mathrm{C}$ with no or limited overshoot (compared to end-of-century budget scenarios with overshoot).

Once net-zero $\mathrm{CO}_{2}$ emissions are reached, however, the mitigation effort in the net-zero budget scenarios with limited overshoot can be relaxed, since no further emissions reductions are necessary. This results in a slow-down, or even decline, of carbon prices while keeping $\mathrm{CO}_{2}$ emissions constant at net zero (Supplementary Fig. 1.1-6). During this phase (in the latter half of the century) the economy accelerates since lower mitigation expenditures are required and GDP growth is becoming higher in the net-zero budget scenarios with no or limited overshoot (compared to the end-of-century budget scenarios).

Perhaps most importantly, we find this GDP rebound in the long term to be by far larger than the upfront dampening effects on GDP due to efforts to limit temperature overshoot. In other words, the higher near-term GDP losses of limiting overshoot are fully compensated by higher GDP growth in the second half of the century (Fig. 2a). The absolute GDP levels in the long term (2100) are thus higher across all models and mitigation scenarios that limit the overshoot (Fig. 2a), which is consistent with the reduced stringency of the target at the end of the time horizon. This observation holds also on the regional level with relatively higher losses in the near term in fossil fuel-exporting regions (Supplementary Fig. 1.1-12). For a 1.5 and $2{ }^{\circ} \mathrm{C}$ target, the long-term GDP (2100) is about $1.2 \%$ higher (range $0.1-2.4 \%$ ) in scenarios that limit overshoot. Similarly, the peak carbon prices over the course of the century-a relevant indicator measuring policy stringency and disruptiveness $s^{25,26}$ - are substantially lower in most scenarios without overshoot (Supplementary Figs. 1.1-6 and 1.1-7). The difference between net-zero budget and end-of-century budget becomes smaller at weaker temperature targets and diminishes fully at high budgets where $\mathrm{CO}_{2}$ emissions do not need to become net zero over the course of the century (depending on the model this corresponds to a budget of $1,000-2,500 \mathrm{GtCO}_{2}$ ).

Across all IAMs we find that accelerating the transformation towards net-zero $\mathrm{CO}_{2}$ emissions would have benefits for the long-term GDP, even without considering the benefits of avoided impacts that are traditionally not included in the type of scenario analysis presented here.

From a methodological perspective, it is important to emphasize that our results are not suggesting that avoiding overshoot is leading to lower 'overall' cumulative mitigation costs over the entire century. The perceived overall cumulative cost of each pathway depends critically on the discount rate and how one weights the near-term GDP losses against the long-term GDP gains ${ }^{24}$. To explore the impact of the discount rate on the overall cumulative costs we conduct an ex-post-sensitivity analysis, systematically varying the discount rate between 0 and 5\% (and apply them to the existing cost pathways of the scenarios). We find that discount rates of less than about $2 \%$ would make the perceived cumulative costs of most 1.5 and $2{ }^{\circ} \mathrm{C}$ scenarios overall less costly without overshoot (see Fig. $2 \mathrm{c}$ for the cumulative GDP losses and Supplementary Fig. 1.1-13 for the net present value (NPV) of the carbon price). Assuming higher discount rates on the other hand would favour relatively delayed mitigation with overshoot. Perhaps most importantly, irrespective of the discount rate, we find long-term GDP in 2100 to be higher in scenarios with limited or no overshoot (Section 1.2 of the Supplementary Information gives a discount-rate sensitivity analysis).

Another important cost factor is the NDCs. Their modest mitigation effort in the near term leads to relatively reduced costs in 2030 (Fig. 2b). The NDCs, however, have negative economic effects from 2040 onwards, where the acceleration of the mitigation effort for limiting temperature to $2^{\circ} \mathrm{C}$ would result in relatively higher GDP losses for the entire century (Fig. 2b).

\section{Net-zero $\mathrm{CO}_{2}$ emissions systems}

Our study explores a range of diverse net-zero $\mathrm{CO}_{2}$ emission systems. The distribution of the emissions reductions across sectors, space and time depends critically on a number of factors, including relative abatement costs, the inertia of sectors against fundamental structural changes and the ability to reduce emissions in different sectors to zero or even further to NNCE. In a zero $\mathrm{CO}_{2}$ emissions 
a

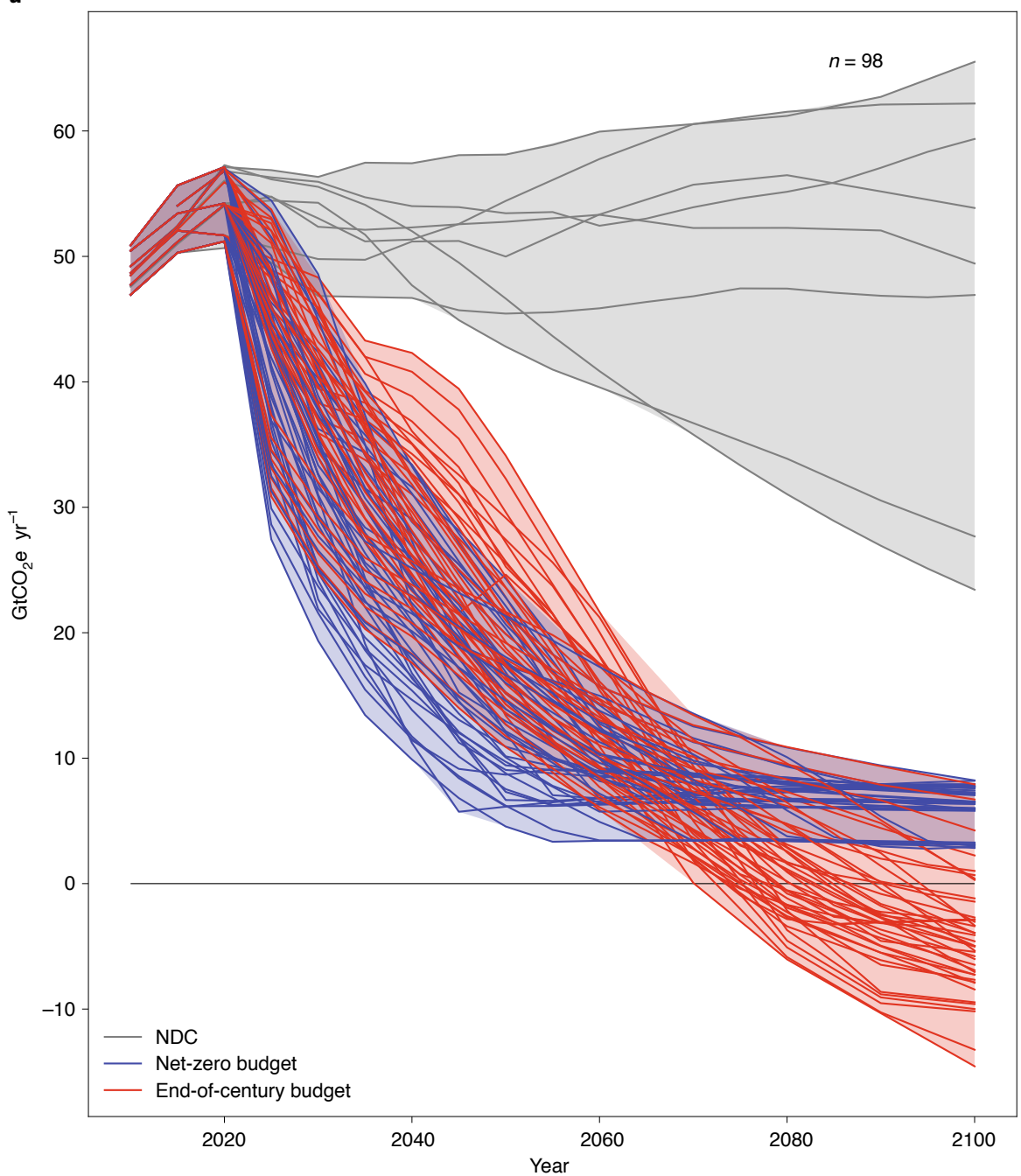

b
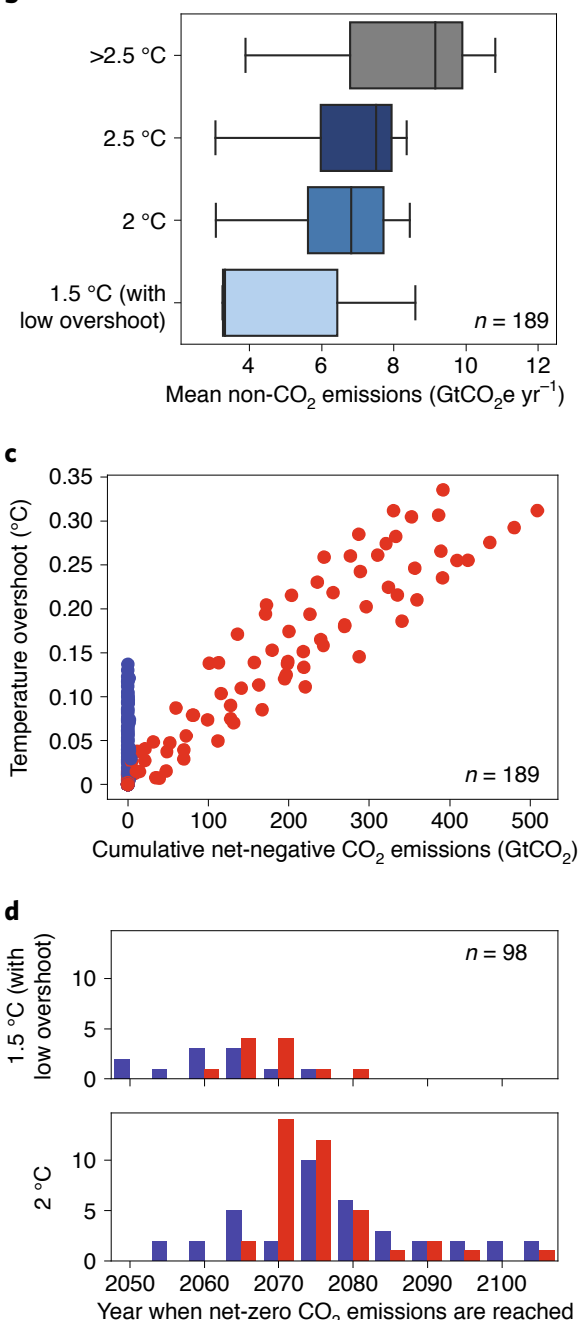

Fig. 1 | Emissions and temperature characteristics. $\mathbf{a}$, GHG emissions in NDC scenarios (grey) compared to stringent mitigation scenarios that reach peak temperatures below $2^{\circ} \mathrm{C}$ with limited overshoot (net-zero budget scenarios, blue) and mitigation scenarios with the same long-term carbon budget with temperature overshoot (end-of-century budget scenarios, red). b. Residual non- $\mathrm{CO}_{2}$ emissions after the point of reaching net-zero $\mathrm{CO}_{2}$ emissions for specified temperature stabilization levels. The box shows the quartiles of the dataset while the whiskers extend to show the rest of the distribution. $\mathbf{c}$, Relationship between cumulative NNCE and resulting temperature drawdown after peak temperature (that is, overshoot). Net-zero scenarios (red) and end-of-century scenarios (blue). d, Timing of when net-zero $\mathrm{CO}_{2}$ emissions are reached. Net-zero budget scenarios consistent with $1.5^{\circ} \mathrm{C}$ (low overshoot) and $2{ }^{\circ} \mathrm{C}$ respectively (blue bars) are compared to scenarios with the same end-of-century carbon budget with net-negative emissions (red bars). The height of the bars indicates the number of scenarios that reach net zero at the specific year.

system, some sectors and regions continue to act as sources of residual emissions, which are balanced by sinks in other sectors/regions that remove $\mathrm{CO}_{2}$ from the atmosphere to achieve overall net-zero emissions (Fig. 3).

The magnitude of the sinks differs across the assessed models, ranging globally from $\sim 5 \mathrm{GtCO}_{2}$ per year (REMIND-MAgPIE and GEM-E3 models) to $>10 \mathrm{GtCO}_{2}$ per year (POLES and WITCH, Fig. 3). Afforestation and reforestation, as well as BECCS (see also sensitivity analysis in Section 1.6 of the Supplementary Information), are responsible for the bulk of the gross negative emissions in the scenarios. Their contributions vary markedly though. AFOLU and energy supply sectors act as sinks, while the demand-side sectors (transport, buildings and industry) are primarily responsible for any of the remaining residual emissions sources. The results emphasize the importance of addressing the residual emissions in these demand sectors, which in turn would lower the pressure on supply-side transformations, including the need to enhance the anthropogenic sink. In some models (for example, REMIND-MAgPIE and GEM-E3), industrial processes, feedstocks and/or the buildings sector reach zero emissions or contribute smaller amounts of NNCE. Electrification, efficiency and demand reductions play a critical role across all demand sectors.

The sectors differ with respect to the timing of when they achieve net-zero $\mathrm{CO}_{2}$ emissions. Globally $\mathrm{CO}_{2}$ emissions reach net zero around $2050-2075$ and $2055-2100$ in $1.5^{\circ} \mathrm{C}$ pathways with low overshoot and $2{ }^{\circ} \mathrm{C}$ pathways, respectively (Fig. $1 \mathrm{~d}$ and Supplementary Fig. 1.1-4). However, in most scenarios, the AFOLU sector is fully decarbonized 10-40 years earlier and the energy supply sector often 10-20 years earlier (Fig. 3c). The demand-side sectors on the other hand (buildings, industry and transport), with many small dispersed and difficult-to-abate emissions sources, do in many instances not reduce emissions to zero throughout the century when considered as part of an integrated net-zero strategy (Fig. 3c). Across demand sectors, limiting demand through improved 


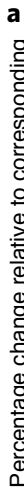

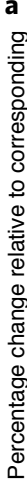
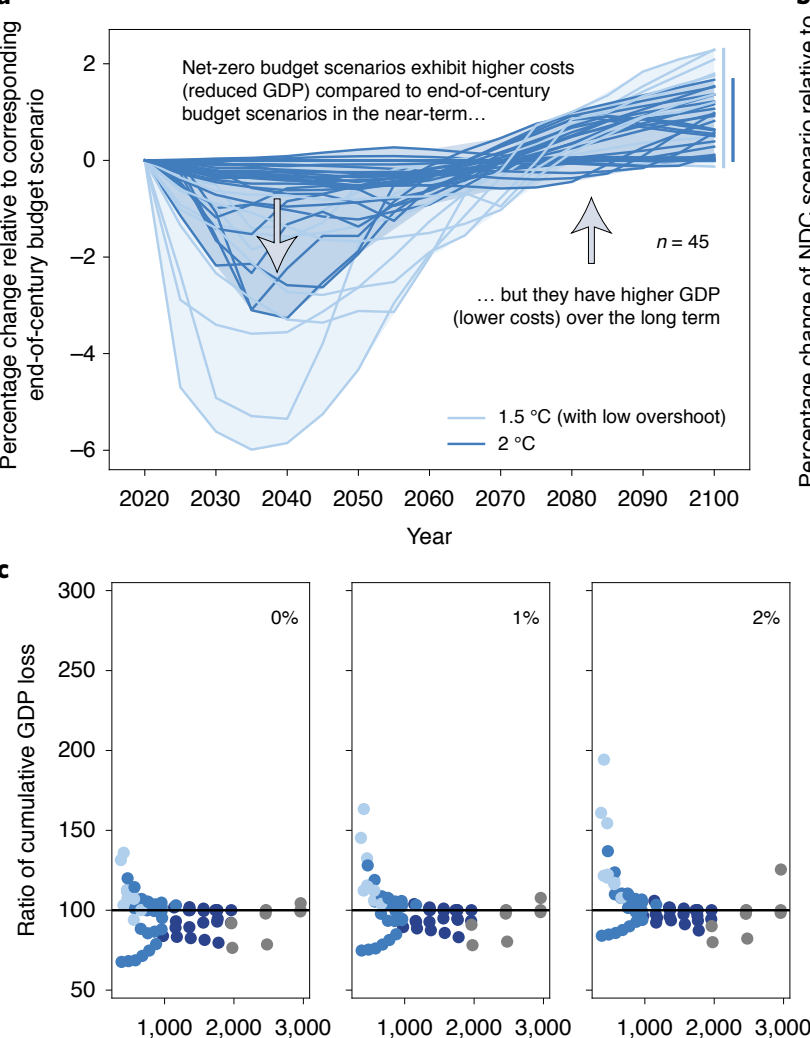

$1,0002,0003,000$

Cumulative net-negative $\mathrm{CO}_{2}$ emissions $\left(\mathrm{GtCO}_{2}\right)$
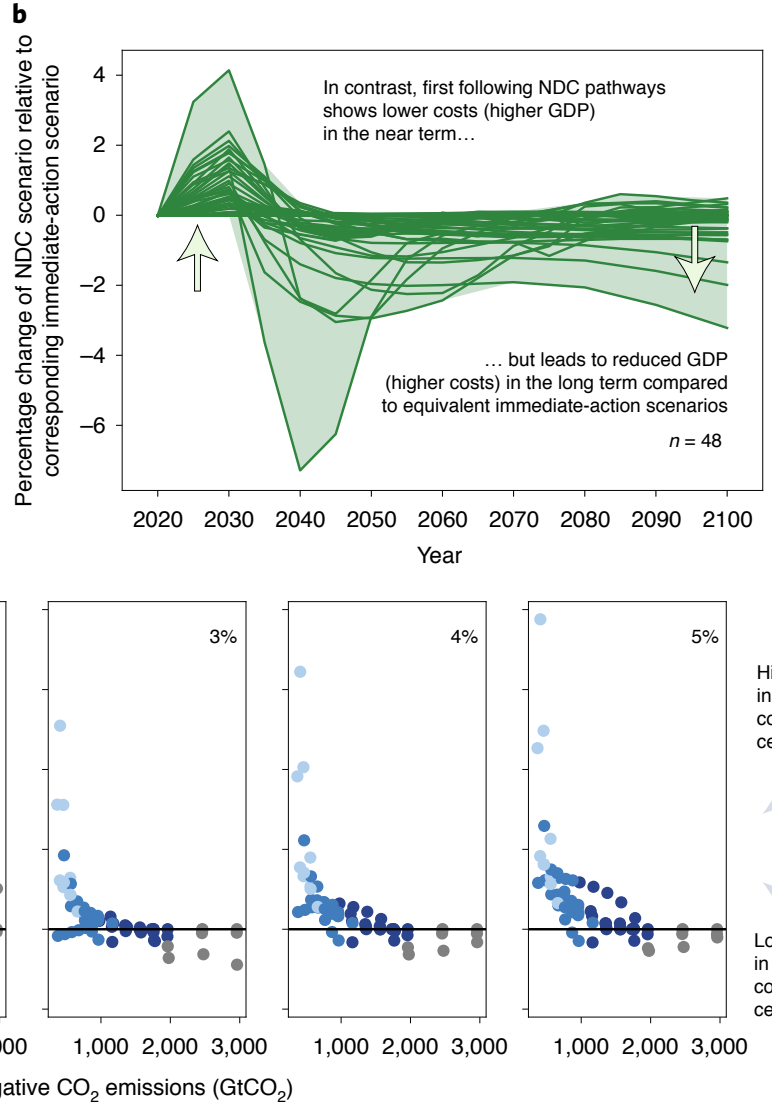

Higher perceived costs in net-zero scenarios century budget scenarios
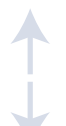

Lower perceived costs in net-zero scenarios compared to end-ofcentury budget scenarios

Fig. 2 | Economic implications of scenarios with increased near-term stringency and limited temperature overshoot. a, Development of GDP in mitigation scenarios with limited overshoot and no NNCE relative to scenarios with overshoot and NNCE in the second half of the century. In the near term, the GDP of net-zero budget scenarios is relatively lower, but this is compensated in the second half of the century where GDP in net-zero budget scenarios grows bigger. $\mathbf{b}$, Development of GDP in immediate-action scenarios relative to scenarios with an equivalent carbon budget, following the NDCs until 2030. In the near term, the GDP of the NDC scenarios is higher because mitigation action is delayed, but this is compensated by 2040 when GDP in the NDC scenario falls below the immediate-action scenarios (and never catches up). c, The ratio of cumulative GDP loss (NPV, 2020-2100) assuming different discount rates (0-5\%). The discount rates are applied exogenously to the GDP pathway of each scenario. The perceived overall costs of each scenario (cumulative GDP loss from mitigation policy) differ for each discount rate, reflecting the different weights of costs over time. The panel shows the NPV price ratio between net-zero budget scenarios with limited overshoot and their corresponding end-of-century carbon budget scenarios (ratio $<100$ means that scenarios with limited overshoot are perceived to be overall less costly under the specific assumptions). Each dot represents the ratio for a pair of scenarios with a specific carbon budget ( $x$ axis). See Supplementary Fig. 1.1-13 showing the same ratios for the NPV of the carbon price. The development of the GDP in the baseline scenarios is shown in Supplementary Fig. 1.1-11.

efficiency and behavioural change, as well as rapid electrification, play an important role. Avoiding non- $\mathrm{CO}_{2}$ emissions is critical in the agricultural sector where reductions of $\mathrm{N}_{2} \mathrm{O}$ and $\mathrm{CH}_{4}$ emissions are achieved. Carbon dioxide removal (CDR) plays three important roles in all scenarios (also in scenarios that avoid NNCE): (1) helping to accelerate emissions reductions early in the century, (2) offsetting residual emissions to achieve net-zero $\mathrm{CO}_{2}$ and (3) achieving net-negative emissions in the long term to reduce warming after the peak (if necessary). See also Section 1.3 on the role of CDR in the Supplementary Information.

Also the timing of when different regions reach net-zero $\mathrm{CO}_{2}$ emissions varies considerably (Fig. 3c). Regions with a larger low-cost CDR potential and large-scale availability of land resources, such as Latin America and the Reforming Economies including Russia, tend to decarbonize first and much earlier than the world average (Supplementary Figs. 1.1-14 to 1.1-16). This sequence in the timing of decarbonization is because the pathways describe a cost-effective response across regions, implicitly assuming that there is some degree of coordination and financial collaboration that allows regions to tap into mitigation options that stretch across regions (when needed). Regions with high projected economic catch-up and continued population growth in the future and/or lower CDR potentials, such as Africa, parts of Asia and the Middle East, thus tend to reach net-zero $\mathrm{CO}_{2}$ emissions relatively later. In some scenarios, these regions even maintain some residual emissions throughout the century. Generally, today's rich economies of the Organisation for Economic Co-operation and Development (OECD) reach net-zero $\mathrm{CO}_{2}$ emissions domestically about the same time as the global average if climate change mitigation is to be achieved cost-effectively. In a world in which rich OECD economies aim at taking up a climate leadership position, or to reflect higher historic responsibility, their net-zero $\mathrm{CO}_{2}$ timing could well be set earlier.

\section{Discussion}

We have shown that scenarios with an accelerated transition towards net-zero emissions avoid a systematic (discounting) bias in favour of temperature overshoot. Furthermore, we identify sectors and regions that may provide an entry point for rapid and deep cuts towards zero $\mathrm{CO}_{2}$ emissions and illustrate that avoiding overshoot would be associated with economic gains in the long term (even without considering benefits of avoided climate impacts). Our study uses a net-zero carbon budget design which is a close proxy for 


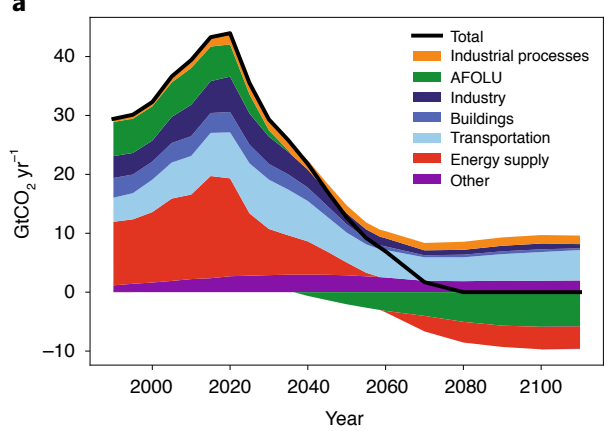

d

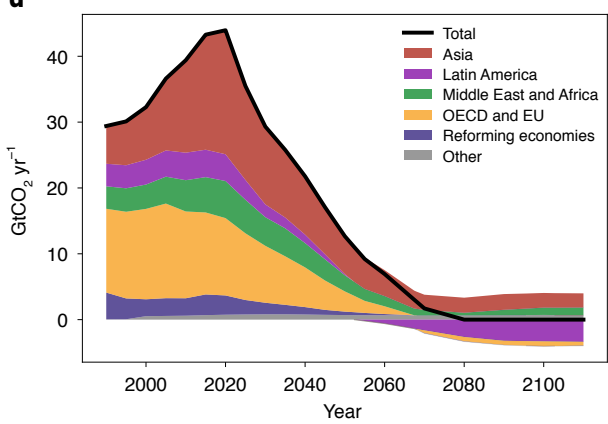

b
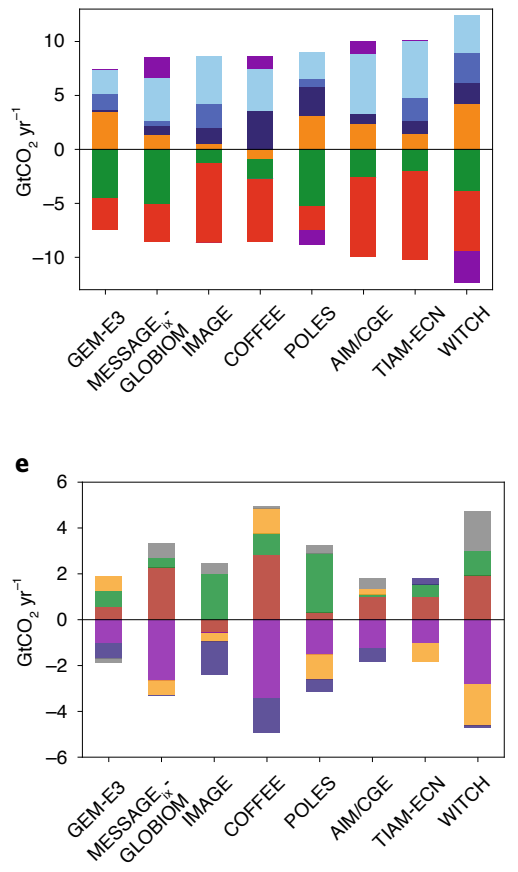

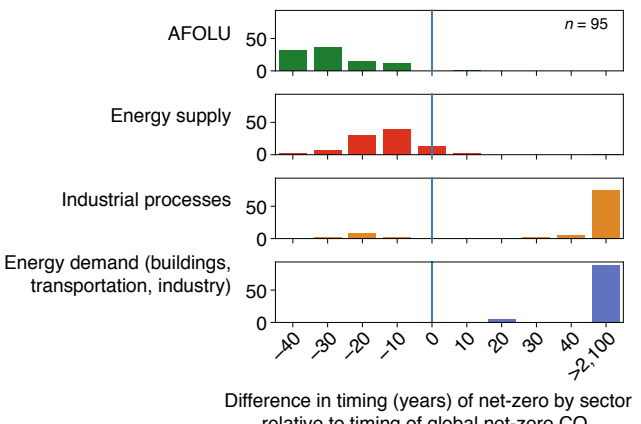

f

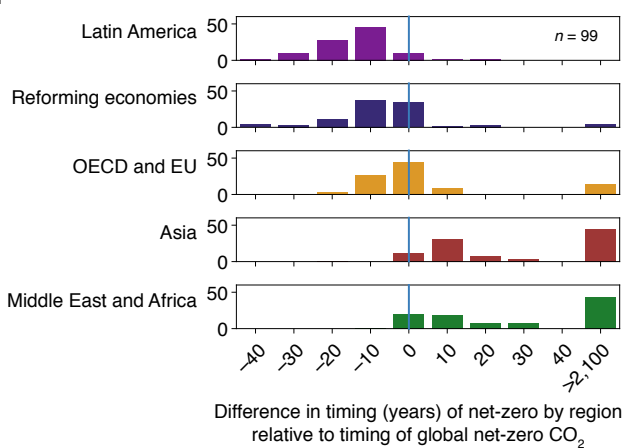

Fig. 3 | Net-zero $\mathrm{CO}_{2}$ emissions systems and the contribution of different sectors and regions in cost-effective scenarios. a, Development of sectoral sinks and sources over time in an illustrative pathway (MESSAGE $\mathrm{ix}_{\mathrm{x}}$-Globiom model and a net-zero budget of 1,000 GtCO ${ }_{2}$ ). b, Results from different models, showing the contribution of different sectors at the time when net-zero $\mathrm{CO}_{2}$ emissions are reached. c, The timing of net-zero for different sectors relative to the timing of net-zero global total $\mathrm{CO}_{2}$ (blue line at zero). d, Development of regional sinks and sources over time in an illustrative pathway

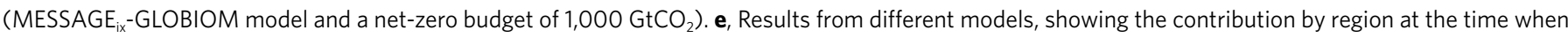
net-zero $\mathrm{CO}_{2}$ emissions are reached. $\mathbf{f}$, The timing of net-zero for different regions relative to the timing of net-zero global total $\mathrm{CO}_{2}$ (blue line at zero). Note: REMIND-MagPie is not shown because, for a carbon budget of $1,000 \mathrm{GtCO}_{2}$, it does not reach net-zero $\mathrm{CO}_{2}$ emissions. The histograms include all pathways that limit temperature to $<2{ }^{\circ} \mathrm{C}$ reporting results at a sufficient level of detail.

peak warming. Other scenario designs, for example, limiting global temperature directly or using different metrics for the temperature equivalence, are possible as well ${ }^{10,12}$ and would affect the substitution dynamics of different greenhouse gases.

Net-zero $\mathrm{CO}_{2}$ emissions systems imply the deployment of CDR measures with very different implications for the sustainability of the overall mitigation portfolio. BECCS may lead to possible trade-offs with sustainable development, depending on the scale of deployment, implementation practice and local context ${ }^{18,27,28}$. The CDR portfolio thus varies across models, providing policy flexibility with respect to technology choices. Some pathways rely on BECCS (for example, REMIND-MAgPIE), while other pathways rely more heavily on nature-based solutions or use more balanced approaches

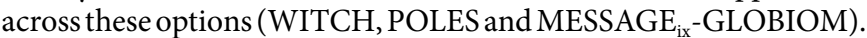
The IAMs do not include all possible CDR options ${ }^{29}$. CDR can serve three purposes in mitigation pathways: it can help to accelerate early emissions reductions, thus supporting achieving net-zero $\mathrm{CO}_{2}$ emissions as soon as possible; it can offset residual emissions from sectors that might be difficult to decarbonize completely; and it can provide a long-term risk-hedging strategy to generate net-negative emissions and gradually reverse warming if desired. In all three instances, deep reductions in gross $\mathrm{CO}_{2}$ emissions remain crucial.

The importance of demand-side measures cannot be overemphasized $^{30-32}$. Generally, efficiency, behavioural change and the deployment of granular and small-scale technologies is enabling rapid technology diffusion and substitution processes ${ }^{33-35}$. In addition, demand-side mitigation is key for reducing residual emissions. Bottlenecks include particularly the industry sector's demand for carbonaceous fuels and the transport sector, as well as the materials and consumption goods sectors. Particularly, material substitution and options for demand-side electrification need to be represented in a more bottom-up and granular fashion in the models.

The regional scenario results indicate opportunities for mitigation and do not imply political feasibility, which would need to consider a diverse set of ethical and other considerations ${ }^{36}$. In fact, we find large differences across regions to reach net-zero $\mathrm{CO}_{2}$ emissions and the pathways suggest that, from an economic perspective, it will be most attractive if some regions act as sources while others act as sinks. Achieving such an effective solution, however, poses a major challenge because it requires international collaboration and markets for cross-regional policy frameworks. In this context, it is encouraging to observe that net-zero emissions targets in a number of key countries/regions, like China ${ }^{37}$, the European Union $(\mathrm{EU})^{38}$, $\operatorname{Japan}^{39}$ and South Korea ${ }^{40}$ are broadly consistent with the pace of the transformation as depicted by our study.

\section{Online content}

Any methods, additional references, Nature Research reporting summaries, source data, extended data, supplementary information, acknowledgements, peer review information; details of author contributions and competing interests; and statements of data and code availability are available at https://doi.org/10.1038/ s41558-021-01215-2.

Received: 13 December 2020; Accepted: 8 October 2021;

Published online: 29 November 2021 


\section{References}

1. McCollum, D. L. et al. Energy investment needs for fulfilling the Paris Agreement and achieving the Sustainable Development Goals. Nat. Energy 3, 589-599 (2018).

2. Bauer, N. et al. Global energy sector emission reductions and bioenergy use: overview of the bioenergy demand phase of the EMF-33 model comparison. Clim. Change https://doi.org/10.1007/s10584-018-2226-y (2018).

3. Luderer, G. et al. Residual fossil $\mathrm{CO}_{2}$ emissions in $1.5-2{ }^{\circ} \mathrm{C}$ pathways. Nat. Clim. Change 8, 626-633 (2018).

4. Riahi, K. et al. The Shared Socioeconomic Pathways and their energy, land use, and greenhouse gas emissions implications: an overview. Glob. Environ. Change 42, 153-168 (2017).

5. Clarke, L. et al. in Climate Change 2014: Mitigation of Climate Change (eds Edenhofer, O. et al.) 413-510 (IPCC, Cambridge Univ. Press, 2014).

6. Rogelj, J. et al. in Special Report on Global Warming of $1.5^{\circ} \mathrm{C}$ (eds Masson-Delmotte, V. et al.) 93-174 (IPCC, WMO, 2018).

7. Riahi, K. et al. Locked into Copenhagen pledges-implications of short-term emission targets for the cost and feasibility of long-term climate goals. Technol. Forecast. Soc. Change 90, 8-23 (2015).

8. Tavoni, M. et al. Post-2020 climate agreements in the major economies assessed in the light of global models. Nat. Clim. Change 5, 119-126 (2015)

9. Azar., C., Johansson, D. J. A. \& Mattsson, N. Meeting global temperature targets-the role of bioenergy with carbon capture and storage. Environ. Res. Lett. https://doi.org/10.1088/1748-9326/8/3/034004 (2013).

10. Tanaka, K. \& O’Neill, B. The Paris Agreement zero-emissions goal is not always consistent with the $1.5^{\circ} \mathrm{C}$ and $2^{\circ} \mathrm{C}$ temperature targets. Nat. Clim. Change 8, 319-324 (2018).

11. Rogelj, J. et al. A new scenario logic for the Paris Agreement long-term temperature goal. Nature 573, 357-363 (2019).

12. Johansson D. J. A., Azar., C., Lehtveer, M. \& Peters, G. P. The role of negative carbon emissions in reaching the Paris climate targets: the impact of target formulation in integrated assessment models. Environ. Res. Lett. https://doi. org/10.1088/1748-9326/abc3fo (2020).

13. Anderson, K. \& Peters, G. The trouble with negative emissions. Science 354, 182-183 (2016).

14. Geden, O. Policy: climate advisers must maintain integrity. Nature 521, 27-28 (2015).

15. Peters, G. P. \& Geden, O. Catalysing a political shift from low to negative carbon. Nat. Clim. Change 7, 619-621 (2017).

16. Rogelij, J., Geden, O., Cowie, A. \& Reisinger, A. Net-zero emissions targets are vague: three ways to fix. Nature 591, 365-368 (2021).

17. Fujimori, S., Rogelj, J., Krey, V. \& Riahi, K. A new generation of emissions scenarios should cover blind spots in the carbon budget space. Nat. Clim. Change 9, 798-800 (2019).

18. de Coninck, H. et al. in Special Report on Global Warming of $1.5^{\circ} \mathrm{C}$ (eds Masson-Delmotte, V. et al.) Ch. 4 (IPCC, WMO, 2018).

19. Fricko, O. et al. The marker quantification of the Shared Socioeconomic Pathway 2: a middle-of-the-road scenario for the 21st century. Glob. Environ. Change 42, 251-267 (2017).

20. MacDougall, A. H. et al. Is there warming in the pipeline? A multi-model analysis of the zero emissions commitment from $\mathrm{CO}_{2}$. Biogeosciences $\mathbf{1 7}$, 2987-3016 (2020).

21. Fuglestvedt, J. et al. Implications of possible interpretations of 'greenhouse gas balance' in the Paris Agreement. Philos. Trans. R. Soc. A 376, 20160445 (2018)
22. A Clean Planet for All: Long-Term Low Greenhouse Gas Emission Development Strategy of the European Union and its Member States (European Commission, 2018).

23. Van Vuuren, D. P. et al. The Representative Concentration Pathways: an overview. Clim. Change 109, 5 (2011).

24. Emmerling, J. et al. The role of the discount rate for emission pathways and negative emissions. Environ. Res. Lett. 14, 104008 (2019).

25. Rogelj, J., McCollum, D. L., O’Neill, B. C. \& Riahi, K. 2020 emissions levels required to limit warming to below $2{ }^{\circ} \mathrm{C}$. Nat. Clim. Change 3 , 405-412 (2013)

26. Kriegler, E. et al. Short term policies to keep the door open for Paris climate goals. Environ. Res. Lett. 13, 074022 (2018).

27. Fuss, S. et al. Negative emissions-Part 2: costs, potentials and side effects. Environ. Res. Lett. 13, 063002 (2018).

28. IPCC: Summary for Policymakers. In Special Report on Climate Change and Land (eds Shukla, P. R. et al.) (WMO, 2019).

29. Realmonte, G. et al. An inter-model assessment of the role of direct air capture in deep mitigation pathways. Nat. Commun. 10, 3277 (2019).

30. Riahi, K. et al. in Global Energy Assessment-Toward a Sustainable Future (eds Johansson, T. B. et al.) 1203-1306 (Cambridge Univ. Press, 2012).

31. Fujimori, S., Kainuma, M., Masui, T., Hasegawa, T. \& Dai, H. The effectiveness of energy service demand reduction: a scenario analysis of global climate change mitigation. Energy Policy 75, 379-391 (2014)

32. Grubler, A. et al. A low energy demand scenario for meeting the $1.5^{\circ} \mathrm{C}$ target and sustainable development goals without negative emission technologies. Nat. Energy 3, 515-527 (2018).

33. Wilson, C. et al. Granular technologies to accelerate decarbonization. Science 368, 36-39 (2020).

34. Grubler, A. et al. A low energy demand scenario for meeting the $1.5^{\circ} \mathrm{C}$ target and sustainable development goals without negative emission technologies. Nat. Energy 3, 515-527 (2018).

35. Creutzig, F. et al. Towards demand-side solutions for mitigating climate change. Nat. Clim. Change 8, 260-263 (2018).

36. Höhne, N., den Elzen, M. \& Escalante, D. Regional GHG reduction targets based on effort sharing: a comparison of studies. Clim. Policy 14, 122-147 (2014).

37. Statement by H.E. Xi Jinping President of the People's Republic of China at the General Debate of the 75th Session of the United Nations General Assembly (Ministry of Foreign Affairs, the People's Republic of China, 2020); https://www.fmprc.gov.cn/mfa_eng/zxxx_662805/t1817098.shtml

38. Submission by Croatia and the European Commission on Behalf of the European Union and its Member States (UNFCCC, 2020); https://unfccc.int/ sites/default/files/resource/HR-03-06-2020\%20EU\%20Submission\%20on\%20 Long\%20term\%20strategy.pdf

39. Policy Speech by the Prime Minister to the 203rd Session of the Diet (Cabinet Public Relations Office, Japan, 2020); https://japan.kantei.go.jp/99_suga/ statement/202010/_00006.html

40. Address by President Moon Jae-in at National Assembly to Propose Government Budget for 2021 (Office of the President, Republic of Korea, 2020); https://english1.president.go.kr/BriefingSpeeches/Speeches/898

Publisher's note Springer Nature remains neutral with regard to jurisdictional claims in published maps and institutional affiliations.

(c) The Author(s), under exclusive licence to Springer Nature Limited 2021 


\section{Methods}

The nine IAM frameworks, drawn on in this study are AIM-Hub (refs. ${ }^{41,42}$ ), COFFEE (ref. ${ }^{43}$ ), GEM-E3 (refs. ${ }^{44,45}$ ), IMAGE (ref. ${ }^{46}$ ), MESSAGE -GLOBIOM (ref. ${ }^{47}$ ), TIAM-ECN (ref. ${ }^{48}$ ), POLES (ref. ${ }^{49}$ ), REMIND-MAgPIE (refs. ${ }^{50,51}$ ) and WITCH-GLOBIOM (refs. ${ }^{52,53}$ ). The models span a wide range from least-cost optimization to computable general equilibrium models and from game-theoretic to recursive-dynamic simulation models. Such diversity is beneficial for shedding light on those model findings that are robust to diverging assumptions and model structures. Of particular importance for the current study is that all models have a detailed coverage of the energy sector and seven out of the nine models in addition represent land-use changes and related mitigation measures in detail. All models, however, represent land-based negative emissions options related to either bioenergy production and/or reforestation. Some of the models consider in addition the possibility of negative emissions through feedstocks in industrial products (GCAM and COPPE) and three models (POLES, WITCH and REMIND-MAgPIE) in addition also considers direct air capture. Cost assumptions of different technological CDR options are summarized in Section 1.4 of the Supplementary Information and a sensitivity analysis on BECCS is provided in Section 1.6 of the Supplementary Information. In terms of macroeconomic representation, our study considers a number of general equilibrium models where price-induced effects on GDP and productivity are computed (for example, GEM-E3, REMIND-MAgPIE, MESSAGE-MACRO and AIM-Hub). These models assume an exogenous reference path for GDP as the basis of which price-induced and path-dependent GDP losses are calculated. The models account for the macroeconomic path-dependency in terms of shifts in capital stocks, investments, saving and consumption patterns.

A common scenario design and modelling protocol was implemented by all models (Supplementary Information Section 2 on modelling protocol). For the mitigation scenarios, the models explored the full scenario space of cumulative $\mathrm{CO}_{2}$ emissions limits of $<3,000 \mathrm{GtCO}_{2}(2018-2100)$ in $100 \mathrm{GtCO}_{2}$ increments (Supplementary Tables 2.1-1 and 2.2-2). We thus assess the lowest attainable budget for each model. In scenarios with no NNCE, sources and sinks across sectors and regions may balance each other out but total $\mathrm{CO}_{2}$ emissions are not allowed to become net negative. Mitigation of non- $\mathrm{CO}_{2}$ GHGs follows the same equivalent carbon price as for $\mathrm{CO}_{2}$ (driven by the cumulative $\mathrm{CO}_{2}$ emissions budget constraint). GHG mitigation on the land sector will hinge on appropriate policy designs that avoid competition over land for food or other basic ecosystem services, water resources and/or biodiversity ${ }^{54-57}$. To account for such possible trade-offs, the models in this study limit land-based mitigation and cap the GHG price effect on the agricultural sector to $<$ US $\$ 200$ per $\mathrm{tCO}_{2} \mathrm{e}$. Some models include, in addition, explicit

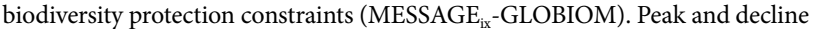
of temperature due the reduction of non- $\mathrm{CO}_{2}$ emissions is between 0 and $0.14^{\circ} \mathrm{C}$ across the models by 2100 (blue dots in Fig. 1b). In contrast to the $\mathrm{CO}_{2}$-induced temperature overshoot, the effect of non- $\mathrm{CO}_{2}$ on overshoot is relatively limited.

The NPi (baseline) scenario broadly incorporates middle-of-the-road socioeconomic conditions based on the second marker baseline scenario from the Shared Socioeconomic Pathways (SSP2) ${ }^{4}$. It also assumes that climate, energy and land-use policies that are currently ratified are implemented (cut-off date 1 July 2019). The NDC scenario builds on the NPi and assumes that the NDCs (both unconditional and conditional NDC actions) as submitted by April 2020 are implemented by 2030 . In addition, we have explored a sensitivity analysis with an update of the NDCs for big emitting countries as submitted in December 2020 (China, EU and Brazil) and find the implications for the emissions and the long-term results to be very small (see Supplementary Information Section 1.5 for a sensitivity analysis). For the NPi and NDC scenarios, a continuation of effort in the long term was assumed. This was implemented by extrapolating the 'equivalent' emissions reductions or carbon price in 2020/2030 (see Supplementary Information, Section 2.2 on NPi and NDC extrapolation methods). We have not considered the impact of the COVID-19 pandemic in a comprehensive way, effectively assuming a full recovery without substantial impact on long-term global emissions ${ }^{58}$. Sensitivity analysis based on selected scenarios indicate only a small impact on mitigation (Supplementary Information Section 2.1). The scenarios explored here, however, can inform governments that aim for 'green' recovery packages ${ }^{59}$, by illustrating the required pace and contribution of key mitigation sectors to reach net-zero $\mathrm{CO}_{2}$ emissions.

The wide range of mitigation costs reflect parametric and structural differences across the models and their resulting marginal abatement cost curves. A classification of the models with respect to abatement costs is provided in ref. ${ }^{60}$. Note that the marginal abatement costs increase rapidly when approaching the (model-specific) attainability frontier and thus reported carbon prices increase considerably $\left(>>1,000\right.$ US\$ per $\left.\mathrm{tCO}_{2}\right)$.

GHG emissions here always refer to the gases of the Kyoto basket (that is, $\mathrm{CO}_{2}$, $\mathrm{CH}_{4}, \mathrm{~N}_{2} \mathrm{O}, \mathrm{HFCs}, \mathrm{PFC}$ and $\mathrm{SF}_{6}$, aggregated with 100 -yr global warming potentials from the IPCC AR5.

The GHG emissions resulting from the different scenarios by the IAM models were fed into the probabilistic reduced-complexity carbon-cycle and climate model MAGICC for the estimation of global mean temperature projections consistent with the scenarios. MAGICC ${ }^{61,62}$ is used in a setup that captures the IPCC AR5 climate sensitivity uncertainty assessment ${ }^{61,63,64}$, as used in the IPCC SR1.5 (ref. ${ }^{6}$ ). If not otherwise specified, the definition of the temperature goals follow the IPCC
SR1.5, that is, limiting the exceedance probability to $<0.34$ for $2{ }^{\circ} \mathrm{C}$ and limiting the exceedance probability for $1.5^{\circ} \mathrm{C}$ (with low overshoot) to $<0.67$ for the peak temperature and $<0.34$ for the year 2100 . Through this methodology we assess the resulting global warming of different pathways and the corresponding peak warming that is associated with the cumulative emissions (budgets) of the scenarios

\section{Data availability}

The underlying data are available at ref. ${ }^{65}$. All scenarios are made accessible online also via the ENGAGE Scenario Portal: https://data.ece.iiasa.ac.at/engage

\section{Code availability}

The models are documented on the common integrated assessment model documentation website (https://www.iamcdocumentation.eu/index.php/ IAMC_wiki) and several have published open source code (for example, REMIND, https://github.com/remindmodel/remind; MESSAGE, https://github.com/iiasa/ message_ix). The code that was used to generate the figures is available at GitHub. For a brief documentation of the models and main concepts see Section 3 of the Supplementary Information. A GitHub repository for the source code of the figures is available at https://github.com/iiasa/ENGAGE-netzero-analysis

\section{References}

41. Fujimori, S., Hasegawa, T., Masui, T. \& Takahashi, K. Land use representation in a global CGE model for long-term simulation: CET vs. logit functions. Food Secur. 6, 685-699 (2014).

42. Fujimori, S., Masui, T. \& Matsuoka, Y. AIM/CGE [basic] Manual Discussion Paper Series (Center for Social and Environmental Systems Research, National Institute for Environmental Studies, 2012).

43. Pedro, R. Development of a Global Integrated Energy Model to Evaluate the Brazilian Role in Climate Change Mitigation Scenarios. DSc thesis, Programa de Planejamento Energético, COPPE/UFRJ (2016).

44. Capros, P. et al. Description of models and scenarios used to assess European decarbonisation pathways. Energy Strategy Rev. 2, 220-230 (2014).

45. GEM-E3 Model Manual 2017 (E3Mlab, 2017).

46. Stehfest, E. et al. Integrated Assessment of Global Environmental Change with IMAGE 3.0. Model Description and Policy Applications (PBL Netherlands Environmental Assessment Agency, 2014).

47. Huppmann, D. et al. The MESSAGE ix $_{\text {ix }}$ Integrated Assessment Model and the ix modeling platform (ixmp): an open framework for integrated and cross-cutting analysis of energy, climate, the environment, and sustainable development. Environ. Model. Softw. 112, 143-156 (2019).

48. van der Zwaan, B., Kober, T., Longa, F. D., van der Laan, A. \& Jan Kramer, G. An integrated assessment of pathways for low-carbon development in Africa. Energy Policy 117, 387-395 (2018).

49. Després, J. et al. POLES-JRC Model Documentation (European Union, 2018).

50. Kriegler, E. Fossil-fueled development (SSP5): an energy and resource intensive scenario for the 21st century. Glob. Environ. Change https://doi. org/10.1016/j.gloenvcha.2016.05.015 (2017).

51. Luderer, G. Economic mitigation challenges: how further delay closes the door for achieving climate targets. Environ. Res. Lett. https://doi. org/10.1088/1748-9326/8/3/034033 (2013).

52. Bosetti, V., Carraro, C., Galeotti, M., Massetti, E. \& Tavoni, M. A World Induced Technical Change Hybrid model. Energy J. 27, 13-38 (2006).

53. Emmerling, J. et al. The WITCH 2016 Model-Documentation and Implementation of the Shared Socioeconomic Pathways (Fondazione Eni Enrico Mattei, 2016).

54. Hasegawa, T. et al. Risk of increased food insecurity under stringent global climate change mitigation policy. Nat. Clim. Change 8, 699-703 (2018).

55. Fujimori, S. et al. Inclusive Climate Change mitigation and food security policy under $1.5^{\circ} \mathrm{C}$ climate goal. Environ. Res. Lett. 13, 074033 (2018).

56 . Leclère, $\mathrm{D}$. et al. Bending the curve of terrestrial biodiversity needs an integrated strategy. Nature 585, 551-556 (2020).

57. Ohashi, H. et al. Biodiversity can benefit from climate stabilization despite adverse side effects of land-based mitigation. Nat. Commun. 10, 5240 (2019).

58. World Energy Outlook 2020 (IEA, 2020).

59. Andrijevic, M., Schleussner, C.-F., Gidden, M. J., McCollum, D. L. \& Rogelj, J. COVID-19 recovery funds dwarf clean energy investment needs. Science 370, 298-300 (2020)

60. Harmsen, M. et al. Integrated assessment model diagnostics: key indicators and model evolution. Environ. Res. Lett. 16, 054046 (2021).

61. Meinshausen, M. et al. Greenhouse-gas emission targets for limiting global warming to $2^{\circ} \mathrm{C}$. Nature 458, 1158-1162 (2009).

62. Meinshausen, M., Raper, S. C. \& Wigley, T. M. Emulating coupled atmosphere-ocean and carbon cycle models with a simpler model, MAGICC6-Part 1: model description and calibration. Atmos. Chem. Phys. 11, 1417-1456 (2011)

63. Rogelj, J., Meinshausen, M., Sedláček, J. \& Knutti, R. Implications of potentially lower climate sensitivity on climate projections and policy. Environ. Res. Lett. 9, 031003 (2014). 
64. Rogelj, J., Meinshausen, M. \& Knutti, R. Global warming under old and new scenarios using IPCC climate sensitivity range estimates. Nat. Clim. Change 2, 248-253 (2012).

65. Riahi, K. et al. ENGAGE Global Scenarios (Version 2.0) (Zenodo, 2021); https://doi.org/10.5281/zenodo.5553932

\section{Acknowledgements}

S. Fujimori, T.H., J.T. and K.O. are supported by the Environment Research and Technology Development Fund (JPMEERF20202002, JPMEERF20211001) of the Environmental Restoration and Conservation Agency of Japan. S. Fujimori and T.H are further supported by the Sumitomo Foundation. K.R., C.B., D.H., J.R., V.B., A.C., A.D., L.D., S. Frank, O.F., M.H., V.K., G.L., L.P., R.S., Z.V., K.F., M.G., F.H., P.K., E.K., A.P., P.R.R.R., G.Ü., B.R., J.T., M.T., D.V. and B.Z. received funding from the European Union's Horizon 2020 research and innovation programme under grant agreement no. 821471 (ENGAGE).

\section{Author contributions}

K.R. designed the study. C.B., O.F. and K.R. coordinated the scenario development and data vetting process. D.H. provided the main figures as well as contributed to analysis.
J.R. conducted the climate runs. V.B., A.M.C., A.D., L.D., S. Frank, S. Fujimori, M.H., T.H., F.H., P.K., V.K., G.L., L.P., A.P., R.S., G.Ü., M.W. and B.v.d.Z. performed the model runs and developed the scenarios; vetting was further carried out by C.B., F.D.L., A.D., J.D., L.D., F.F., S. Frank, O.F., S. Fujimori, M.G., T.H., D.H., K.K., E.K., L.N., K.O., L.P., P.R., B.v.R., J.T., M.T., D.v.V., Z.V., M.W. and B.Z. K.R. prepared the first draft and all authors contributed to writing the paper.

\section{Competing interests}

The authors declare no competing interests.

\section{Additional information}

Supplementary information The online version contains supplementary material available at https://doi.org/10.1038/s41558-021-01215-2.

Correspondence and requests for materials should be addressed to Keywan Riahi. Peer review information Nature Climate Change thanks Sha Yu and the other, anonymous, reviewer(s) for their contribution to the peer review of this work.

Reprints and permissions information is available at www.nature.com/reprints. 